\title{
Efficacy of Variable Tetraconazole Rates Against Cercospora beticola Isolates with Differing In Vitro Sensitivities to DMI Fungicides
}

Melvin D. Bolton, United States Department of Agriculture-Agricultural Research Service, Northern Crop Science Laboratory, Fargo, ND, and the Department of Plant Pathology, North Dakota State University, Fargo; Viviana Rivera-Varas and Luis E. del Río Mendoza, Department of Plant Pathology, North Dakota State University, Fargo; Mohamed F. R. Khan, Department of Plant Pathology, North Dakota State University, Fargo, and University of Minnesota, St. Paul; and Gary A. Secor, Department of Plant Pathology, North Dakota State University, Fargo

\begin{abstract}
Bolton, M. D., Rivera-Varas, V., del Río Mendoza, L. E., Khan, M. F. R., and Secor, G. A. 2012. Efficacy of variable tetraconazole rates against Cercospora beticola isolates with differing in vitro sensitivities to DMI fungicides. Plant Dis. 96:1749-1756.

Cercospora leaf spot (CLS) of sugar beet is caused by the fungus Cercospora beticola. CLS management practices include the application of the sterol demethylation inhibitor (DMI) fungicides tetraconazole, difenoconazole, and prothioconazole. Evaluating resistance to DMIs is a major focus for CLS fungicide resistance management. Isolates were collected in 1997 and 1998 (baseline sensitivity to tetraconazole, prothioconazole, or difenoconazole) and 2007 through 2010 from the major sugar-beet-growing regions of Minnesota and North Dakota and assessed for in vitro sensitivity to two or three DMI fungicides. Most (47\%) isolates collected in 1997-98 exhibited 50\% effective concentration $\left(\mathrm{EC}_{50}\right)$ values for tetraconazole of $<0.01 \mu \mathrm{g} \mathrm{ml}{ }^{-1}$, whereas no isolates could be found in this $\mathrm{EC}_{50}$ range in 2010. Since 2007, annual median and mean tetraconazole $\mathrm{EC}_{50}$ values have generally been increasing, and the frequency of isolates with $\mathrm{EC}_{50}$ values $>0.11 \mu \mathrm{g} \mathrm{ml}^{-1}$ increased from 2008 to 2010 . In contrast, the frequency of isolates with $\mathrm{EC}_{50}$ values for prothioconazole of $>1.0 \mu \mathrm{g} \mathrm{ml}^{-1}$ has been decreasing since 2007. Annual median difenoconazole $\mathrm{EC}_{50}$ values appears to be stable, although annual mean $\mathrm{EC}_{50}$ values generally have been increasing for this fungicide. Although $\mathrm{EC}_{50}$ values are im-

portant for gauging fungicide sensitivity trends, a rigorous comparison of the relationship between in vitro $\mathrm{EC}_{50}$ values and loss of fungicide efficacy in planta has not been conducted for $C$. beticola. To explore this, 12 isolates exhibiting a wide range of tetraconazole $\mathrm{EC}_{50}$ values were inoculated to sugar beet but no tetraconazole was applied. No relationship was found between isolate $\mathrm{EC}_{50}$ value and disease severity. To assess whether $\mathrm{EC}_{50}$ values are related to fungicide efficacy in planta, sugar beet plants were sprayed with various dilutions of Eminent, the commercial formulation of tetraconazole, and subsequently inoculated with isolates that exhibited very low, medium, or high tetraconazole $\mathrm{EC}_{50}$ values. The high $\mathrm{EC}_{50}$ isolate caused significantly more disease than isolates with medium or very low $\mathrm{EC}_{50}$ values at the field application rate and most reduced rates. Because in vitro sensitivity testing is typically carried out with the active ingredient of the commercial fungicide, we investigated whether loss of disease control was the same for tetraconazole as for the commercial product Eminent. The high $\mathrm{EC}_{50}$ isolate caused more disease on plants treated with tetraconazole than Eminent but disease severity was not different between plants inoculated with the very low $\mathrm{EC}_{50}$ isolate.
\end{abstract}

Cercospora leaf spot (CLS), caused by the fungus Cercospora beticola (Sacc.), is the most important foliar disease of sugar beet (Beta vulgaris L.) in North Dakota and Minnesota (39). The disease causes a reduction in root harvest weight and extractable sucrose due to the loss of photosynthetic capacity and diversion of photosynthate from roots for foliage regeneration (12). Outbreaks occur during conditions of protracted warm and humid weather after crop canopies close (27). Conidia are produced as early as 7 days after initial infection (12), thereby raising inoculum levels quickly during favorable conditions. CLS control measures include the use of resistant sugar beet varieties and crop rotation but the disease is managed most effectively only when these measures are combined with timely fungicide applications $(20,27,39)$.

Sugar beet growers in North Dakota and Minnesota have faced cyclical periods of CLS control where fungicide efficacy remains high for a period of time but is followed shortly by reduced fungi-

Corresponding author: M. D. Bolton, E-mail: Melvin.Bolton@ars.usda.gov

Mention of trade names or commercial products in this publication is solely for the purpose of providing specific information and does not imply recommendation or endorsement by the United States Department of Agriculture.

Accepted for publication 13 June 2012.

http://dx.doi.org/10.1094/PDIS-03-12-0255-RE

This article is in the public domain and not copyrightable. It may be freely reprinted with customary crediting of the source. The American Phytopathological Society, 2012. cide sensitivity in $C$. beticola populations, most often due to widespread and repeated use of fungicides of the same or similar chemistries (39). For example, growers relied on three benzimidazole fungicides in the late 1970 s but resistance quickly developed in North Dakota and Minnesota $C$. beticola populations, resulting in an epidemic in $1981(5,41)$. Thereafter, growers relied on triphenyltin hydroxide to control CLS but resistance to this chemistry was reported in $1994(6,7)$ and was widespread in the region by 1996 (8). Optimal environmental conditions and a $C$. beticola population resistant to several of the most widely used fungicides led to a major CLS epidemic in 1998, which resulted in estimated losses over $\$ 100$ million in Minnesota and North Dakota due to reduced yield and costs associated with fungicide application (39). In 1999, the Environmental Protection Agency granted an emergency exemption for growers to use the triazole or sterol demethylation inhibitor (DMI) fungicide tetraconazole. Currently, the most widely used DMIs in Minnesota and North Dakota are tetraconazole, difenoconazole, and prothioconazole; the latter two registered for CLS control in 2008 (39). In addition to North Dakota and Minnesota, fungicide resistance in C. beticola has been reported in several sugar-beet-growing regions worldwide (17). Most recently, resistance to strobilurin or quinone outside inhibitor (QoI) fungicides has been reported in Michigan (2).

DMIs have gained popularity due to protective and curative properties and low levels of phytotoxicity $(10,37)$. DMI-resistant isolates initially were thought to cause less disease than DMIsensitive isolates, suggesting that DMI resistance would not become widespread in field populations $(11,13)$. However, established resistance to DMIs has been reported in many fungal pathogens $(30,32,43)$, including $C$. beticola $(1,23)$. DMIs are inhibitors 
of sterol P450 14 $\alpha$-demethylase (CYP51), a protein required for ergosterol biosynthesis in fungi (17). Resistance to DMIs in $C$. beticola was recently shown to be related to overexpression of CbCyp51 (1). Although the exact mechanism remains to be identified, $C b C y p 51$ was overexpressed in resistant isolates, and was induced further upon exposure to tetraconazole (1).

Fungicide sensitivity of field isolates can be measured by calculating $50 \%$ effective concentration $\left(\mathrm{EC}_{50}\right)$ values $(14,25,26,30,37-$ $39,43)$. The $\mathrm{EC}_{50}$ value is the concentration of fungicide in media that reduces fungal growth or spore germination by $50 \%$ compared with growth on nonamended media (38). $\mathrm{EC}_{50}$ values significantly higher than baseline sensitivity indicate reduced sensitivity, and possibly resistance, to a fungicide. Despite a history of CLS control problems, there have been no major CLS outbreaks since 1998 in North Dakota and Minnesota (39). Although this may be attributed to current fungicide management strategies, a rigorous comparison of the relationship between in vitro $\mathrm{EC}_{50}$ values and loss of fungicide efficacy in planta has not been conducted for $C$. beticola. Because $\mathrm{EC}_{50}$ values are currently used to measure fungicide sensitivity trends in $C$. beticola populations from Minnesota and North Dakota (39), knowledge of the $\mathrm{EC}_{50}$ value at which DMI efficacy is reduced is an important component of fungicide resistance management in this pathosystem.

Economic constraints as well as potential and perceived environmental concerns from pesticide application favor judicious use of fungicides. In some locations, growers may apply reduced fungicide rates in attempts to decrease inputs and increase profits. However, reduced rates may give a sublethal dose to a portion of a field population, which may increase the frequency of mutations in a location and accelerate the evolution of fungicide resistance (15) or cause increased disease severity (14). As part of our ongoing research on fungicide resistance management in this pathosystem, we are interested in the relationship between reduced sensitivity to fungicides as measured by $\mathrm{EC}_{50}$ values and the loss of disease control at field, or lower, fungicide rates to provide greater translational meaning of $\mathrm{EC}_{50}$ values. Tetraconazole was the primary focus in this study because it was the first registered of the three DMI fungicides most commonly applied today. The objectives of this study were to (i) examine $\mathrm{DMI} \mathrm{EC}_{50}$ values from $C$. beticola isolates collected from sugar-beet-growing regions of Minnesota and North Dakota, (ii) determine whether isolate $\mathrm{EC}_{50}$ value is related to disease severity, (iii) determine whether isolate $\mathrm{EC}_{50}$ value is related to fungicide efficacy in planta, and (iv) determine whether the efficacy of tetraconazole was the same for the commercial formulation Eminent.

\section{Materials and Methods}

Sample collection and fungal isolation. Sugar beet leaves with CLS symptoms were collected from commercial fields of the American Crystal Sugar Company, Minn-Dak Farmers Cooperative, and Southern Minnesota Beet Sugar Cooperative, which represent all sugar beet production areas in Minnesota and eastern North Dakota. Samples were received from all three cooperatives in 1997, 1998, 2007, 2008, 2009, and 2010. Leaves were processed immediately upon arrival at the laboratory. Conidia were harvested by applying $50 \mu \mathrm{l}$ of Tween water (T-water; $0.06 \%$ [vol/vol] Tween 20 [Sigma-Aldrich] and $0.02 \%$ [wt/vol] filter-sterilized ampicillin added after the solution had been autoclaved) to a $C$. beticola leaf spot. The leaf spot was gently scraped with a pipette tip to liberate conidia into the T-water. The conidia-laden T-water was collected and placed into a $1.5-\mathrm{ml}$ microcentrifuge tube. This process was repeated for five spots on each of five leaves that represented a field. The T-water from each spot was combined into the same microcentrifuge tube to make a composite of 25 samples for each field. Each composite sample $(100 \mu \mathrm{l})$ was transferred to a water agar plate $(1.5 \%$ [wt/vol] agar [Difco Laboratories] and $0.02 \%$ [wt/vol] filter-sterilized ampicillin added after the solution had been autoclaved) and incubated for $24 \mathrm{~h}$ at $22^{\circ} \mathrm{C}\left( \pm 1^{\circ} \mathrm{C}\right)$ to initiate conidia germination. One germinated conidium was transferred to a clarified V8-medium plate $(10 \%$ [vol/vol] clarified V8 juice
[Campbell's Soup Co.], 0.5\% [wt/vol] $\mathrm{CaCO}_{3}$, and $1.5 \%$ [wt/vol] agar [Difco Laboratories]) and incubated at $25^{\circ} \mathrm{C}$ for 2 weeks. This single spore-derived colony was considered the representative isolate for that respective field and was the source inoculum for subsequent fungicide sensitivity assays or inoculation experiments. This process was repeated for each field in the survey.

Fungicide sensitivity assays. Sensitivity of each $C$. beticola isolate, as measured by $\mathrm{EC}_{50}$ value, was calculated for tetraconazole, prothioconazole, and difenoconazole, which are active ingredients in Eminent 125SL (Sipcam Agro), Proline 480 SC (Bayer CropScience), and Inspire XT 2.08 EC (Syngenta), respectively. EC 50 values were calculated as described by Secor and Rivera (38) for all three fungicides, with the exception that $\mathrm{EC}_{50}$ values were not calculated for prothioconazole in 2010. Briefly, agar plugs $(5 \mathrm{~mm}$ each) were removed from the leading edge of colony growth of the original nonamended V8-agar plates described above and placed on V8-agar plates amended with serial 10-fold dilutions of active ingredient from 0.001 to $1.0 \mu \mathrm{g} \mathrm{ml}^{-1}$. After 15 days, fungal radial growth was measured on each plate in the dilution series, compared with growth on nonamended water agar medium, and used to calculate an $\mathrm{EC}_{50}$ value for each isolate.

Plant growth, fungicide treatments, inoculations, and experimental design. Sugar beet seed of '4012RR' (Syngenta Seeds) were planted into 25 -cm-diameter (8.5-liter) plastic pots filled with Sunshine potting soil mix number 1 (Sun Gro Horticulture). Three seeds were planted per pot. Pots were placed in a greenhouse with an average daytime temperature of $24^{\circ} \mathrm{C}$, an average nighttime temperature of $16^{\circ} \mathrm{C}$, and a $16-\mathrm{h}$ photoperiod. Plants were watered as needed and each pot was thinned to one healthy plant after seedling establishment. At 5 to 6 weeks after planting, which represents the stage at which at least six fully expanded leaves were present, plants were used in experiments described below.

Fungicide treatments for all experiments were administered to plants with a Generation III Research Track chamber sprayer (DeVries Manufacturing) calibrated to deliver 187 liters ha ${ }^{-1}$ by compressed air at $138 \mathrm{kPa}$ through a TeeJet 8001E nozzle (Spraying Systems Co.). Plants were allowed to dry for 4 to $6 \mathrm{~h}$ before being inoculated.

Spores were produced following the methodology described by Secor and Rivera (38) using the control plates from fungicidesensitive assays described earlier. Plants were inoculated with a suspension of 40,000 spores $\mathrm{ml}^{-1}$ delivered with a Generation III Research Track chamber sprayer equipped with a TeeJet $8002 \mathrm{E}$ nozzle (Spraying Systems Co.) set to $207 \mathrm{kPA}$. The sprayer moved at $2.6 \mathrm{~km} / \mathrm{h}$. After inoculation, plants were incubated for 5 days at 95 to $100 \%$ relative humidity in a semi-transparent plastic tent on greenhouse benches with daily $16 \mathrm{~h}$ of supplemental light and average daytime and nighttime temperatures of 35 and $22^{\circ} \mathrm{C}$, respectively. At the end of the incubation period, plants were removed from tents and grown in the greenhouse with average daytime and nighttime temperatures of 24 and $16^{\circ} \mathrm{C}$, respectively, and a $16-\mathrm{h}$ photoperiod. Pots were watered as needed.

Experiment I. This experiment was designed to assess whether CLS disease severity was influenced by in vitro sensitivity to tetraconazole. Isolate sensitivity to tetraconazole was divided into four arbitrary $\mathrm{EC}_{50}$ categories: very low $\left(\mathrm{EC}_{50} \leq 0.01 \mu \mathrm{g} \mathrm{ml} \mathrm{m}^{-1}\right)$, low $\left(\mathrm{EC}_{50}\right.$ between 0.011 and $\left.0.10 \mu \mathrm{g} \mathrm{ml}^{-1}\right)$, medium $\left(\mathrm{EC}_{50}\right.$ between 0.11 and $\left.1.0 \mu \mathrm{g} \mathrm{ml}^{-1}\right)$, and high $\left(\mathrm{EC}_{50}>1.0 \mu \mathrm{g} \mathrm{ml}^{-1}\right)$. Three $C$. beticola isolates from each category were arbitrarily chosen from the library of isolates for plant inoculations as described.

Plants were arranged in a randomized complete block (RCB) design both in the humidity chamber and in the greenhouse. There were six replications per trial and three plants per replication. The entire experiment was conducted two times.

Experiment II. Greenhouse trials were designed to determine the impact of increased insensitivity to tetraconazole on disease control. C. beticola isolates 08-640, 09-318, and 09-398, which exhibited very low, medium, and high $\mathrm{EC}_{50}$ values, respectively, for tetraconazole were chosen for this study because they caused similar disease levels on sugar beet (see Results). Plants were sprayed 
with solutions of Eminent 125SL as described. This commercial formulation of tetraconazole was applied at the recommended field rate of 0.948 liter $\mathrm{ha}^{-1}(\mathrm{X})$ and at $0.1 \mathrm{X}, 0.01 \mathrm{X}, 0.001 \mathrm{X}$, and $0.0001 \mathrm{X}$. Plants sprayed with water were used as controls. Isolates were inoculated on sugar beet plants as described above.

Treatments were organized using an RCB design with a threeby-six factorial arrangement during and after incubation in the humidity chamber. There were six replications per trial each with one plant. The entire experiment was conducted twice.

Experiment III. This experiment was designed to compare the efficacy of control provided by the application of tetraconazole technical and commercial grades. The former is a powder that has 95\% active ingredient and the latter, Eminent 125SL, is a soluble liquid commercial formulation with $11.6 \%$ (wt/wt) active ingredient. Plants were sprayed with either of these formulations at a tetraconazole concentration of $625 \mu \mathrm{g} \mathrm{ml}^{-1}$, which is equivalent to the recommended field rate of Eminent ( 0.948 liter ha $\left.{ }^{-1}\right)$, or with pure water. The fungicides and water were applied on plants as described for previous experiments. Sprayed plants were inoculated with spores of $C$. beticola isolates 08-640 and 09-398, which exhibited very low and high tetraconazole $\mathrm{EC}_{50}$ values, respectively. Inoculation was carried out as described for previous experiments.

Treatments were organized using an RCB design with a two-bythree factorial arrangement in both the humidity chamber and the greenhouse after the high humidity period. There were three replications per trial and six plants per replicate. The entire experiment was conducted twice.

Disease quantification and statistical analysis. Disease severity in all experiments was assessed 3 weeks after inoculation by counting the number of leaf spots caused by $C$. beticola on the four oldest leaves of each plant. Datum produced from each leaf was considered an observation. The data were transformed to a CLS rating system (19) with modifications. Leaves were placed into 10 categories based on the number of spots per leaf: category 1 represented leaves with 1 to 5 spots, category 2 was 6 to 12 spots, category 3 was 13 to 25 spots, category 4 was 26 to 50 spots, category 5 was 51 to 75 spots, category 6 was 76 to 99 spots, category 7 was 100 to 124 spots, category 8 was 125 to 149 spots, category 9 was 150 to 200 spots, and category 10 was more than 200 spots. This rating system is a continuous scale and can be analyzed using parametric statistical methods. However, it may be considered statistically inappropriate to do so in the strict sense (34). Consequently, we used the method proposed by Shah and Madden (40) to analyze the data. In this method, statistical hypotheses are proposed in terms of normalized distribution, the null hypothesis indicates that treatments have no effect, and the alternative hypothesis is that at least one of the treatments is different. The median score for disease severity provides a summary of the central value for each of the treatments. The mean ranks for each treatment were calculated from these medians and used to estimate relative treatment effects. The confidence intervals for each treatment effect, calculated using the SAS macro created by Brunner and colleagues as cited by Shah and Madden (40), were used to compare the treatments. In order to further characterize the reaction of the population to the three fungicides, box plots were produced.

\section{Results}

DMI resistance survey of $\boldsymbol{C}$. beticola field isolates. $\mathrm{EC}_{50}$ values were calculated for two or three DMI fungicides for 2,649 isolates (Table 1). C. beticola populations exhibited different sensitivity trends to these compounds over the period of study. Populations collected in 2007 through 2010 exhibited a decreased shift in DMI sensitivity to tetraconzole compared with baseline values (Table 1; Fig. 1). The percentage of samples with tetraconazole $\mathrm{EC}_{50}$ values $<0.01 \mu \mathrm{g} \mathrm{ml}^{-1}$ fell from $47 \%$ in $1997-98$ to $<23 \%$ in 2008 and to zero in 2010, while the percentage of isolates in $\mathrm{EC}_{50}$ ranges of 0.11 to $1.0 \mu \mathrm{g} \mathrm{ml}^{-1}$ and $>1.0 \mu \mathrm{g} \mathrm{ml}^{-1}$ increased since 2008 (Table

Table 1. Sensitivity of Cercospora beticola isolates to three demethylation inhibitor fungicides ${ }^{\mathrm{a}}$

\begin{tabular}{|c|c|c|c|c|c|c|}
\hline \multirow[b]{2}{*}{ Year, $\mathrm{EC}_{50}$ range $^{\mathrm{b}}$} & \multicolumn{2}{|c|}{ Tetraconazole } & \multicolumn{2}{|c|}{ Difenoconazole } & \multicolumn{2}{|c|}{ Prothioconazole } \\
\hline & $n$ & $\%$ & $n$ & $\%$ & $n$ & $\%$ \\
\hline \multicolumn{7}{|l|}{ 1997-98 (baseline) } \\
\hline$<0.01$ & 47 & 47.0 & 1 & 2.9 & 11 & 31.4 \\
\hline 0.011 to 0.10 & 33 & 33.0 & 22 & 52.4 & 12 & 34.3 \\
\hline 0.11 to 1.0 & 20 & 20.0 & 19 & 45.2 & 12 & 34.3 \\
\hline$>1.0$ & 0 & 0.0 & 0 & 0.0 & 0 & 0.0 \\
\hline$>0.0$ & 100 & 100.0 & 42 & 100 & 35 & 100 \\
\hline \multicolumn{7}{|l|}{2007} \\
\hline$<0.01$ & 249 & 22.6 & 67 & 6.1 & 5 & 0.5 \\
\hline 0.011 to 0.10 & 432 & 39.2 & 896 & 81.2 & 33 & 3.0 \\
\hline 0.11 to 1.0 & 318 & 28.8 & 81 & 7.3 & 628 & 56.9 \\
\hline$>1.0$ & 104 & 9.4 & 59 & 5.4 & 437 & 39.6 \\
\hline$>0.0$ & 1,103 & 100.0 & 1,103 & 100.0 & 1,103 & 100.0 \\
\hline \multicolumn{7}{|l|}{2008} \\
\hline$<0.01$ & 194 & 23.1 & 46 & 5.5 & 2 & 0.2 \\
\hline 0.011 to 0.10 & 445 & 53.0 & 618 & 73.6 & 290 & 34.5 \\
\hline 0.11 to 1.0 & 97 & 11.5 & 95 & 11.3 & 419 & 49.9 \\
\hline$>1.0$ & 104 & 12.4 & 81 & 9.6 & 129 & 15.4 \\
\hline$>0.0$ & 840 & 100.0 & 840 & 100.0 & 840 & 100.0 \\
\hline \multicolumn{7}{|l|}{2009} \\
\hline$<0.01$ & 8 & 2.0 & 10 & 2.5 & 19 & 4.8 \\
\hline 0.011 to 0.10 & 207 & 52.5 & 136 & 34.6 & 339 & 86.3 \\
\hline 0.11 to 1.0 & 150 & 38.1 & 211 & 53.7 & 33 & 8.4 \\
\hline$>1.0$ & 29 & 7.4 & 36 & 9.2 & 2 & 0.5 \\
\hline$>0.0$ & 394 & 100.0 & 393 & 100.0 & 393 & 100.0 \\
\hline \multicolumn{7}{|l|}{2010} \\
\hline$<0.01$ & 0 & 0.0 & 1 & 0.5 & $\ldots$ & $\ldots$ \\
\hline 0.011 to 0.10 & 81 & 38.2 & 149 & 70.0 & $\ldots$ & $\ldots$ \\
\hline 0.11 to 1.0 & 90 & 42.5 & 45 & 21.1 & $\ldots$ & $\ldots$ \\
\hline$>1.0$ & 41 & 19.3 & 18 & 8.4 & $\ldots$ & $\ldots$ \\
\hline$>0.0$ & 212 & 100.0 & 213 & 100.0 & $\ldots$ & $\ldots$ \\
\hline
\end{tabular}

a Symbols: $n=$ umber of isolates in $\mathrm{EC}_{50}$ range for specified year, $\%=$ percentage of isolates in $\mathrm{EC}_{50}$ range for specified year, and $\ldots$ indicates not assessed.

${ }^{\mathrm{b}}$ The $50 \%$ effective concentration $\left(\mathrm{EC}_{50}\right)$ values $\left(\mu \mathrm{g} \mathrm{ml}{ }^{-1}\right)$ were calculated for tetraconazole, prothioconazole, and difenoconazole as described $(38)$ and placed in ranges for each year. 
1). Further, between 2007 and 2010, the median $\mathrm{EC}_{50}$ values for tetraconazole increased from 0.08 to $0.32 \mu \mathrm{g} \mathrm{m}^{-1}$ and the mean $\mathrm{EC}_{50}$ values increased from 0.23 to $0.40 \mu \mathrm{g} \mathrm{ml}^{-1}$ (Fig. 1). In contrast, the median $\mathrm{EC}_{50}$ values for prothioconazole fell from 0.80 to
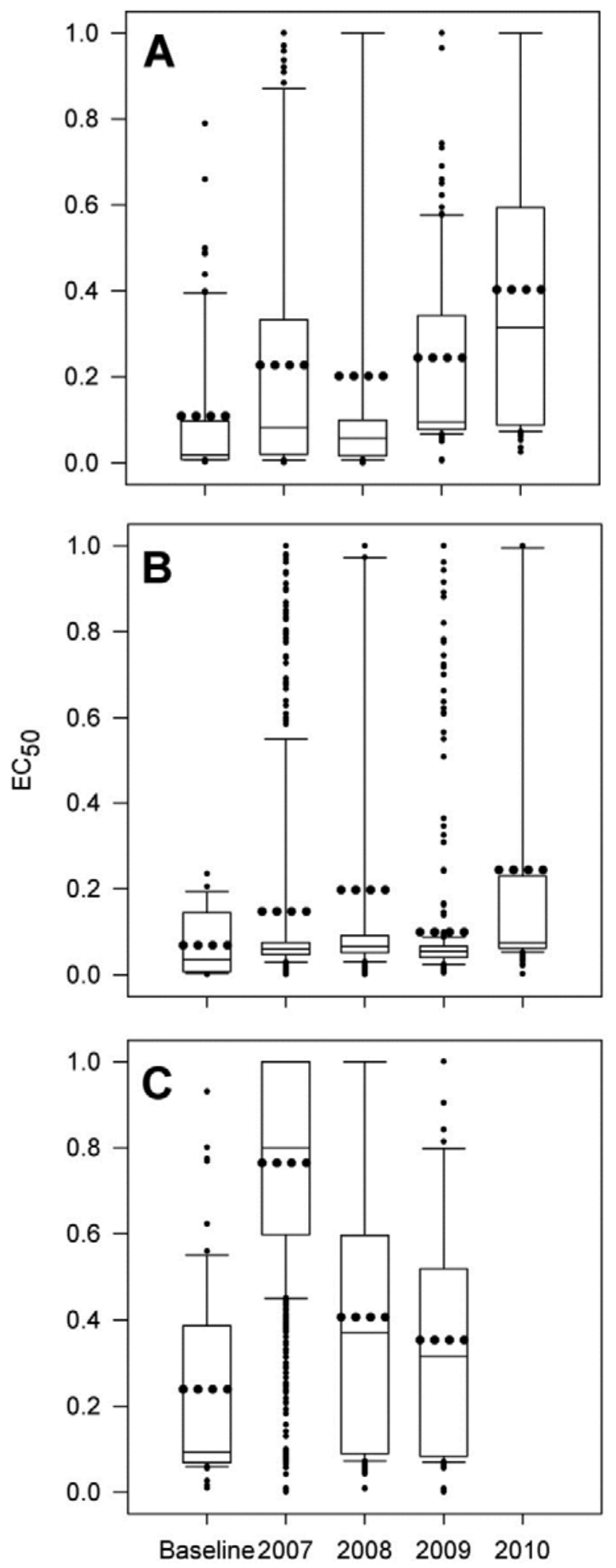

Fig. 1. Sensitivity (50\% effective concentration $\left[E C_{50}\right]$ values) of Cercospora beticola isolates collected from sugar beet fields in North Dakota and Minnesota from 2007 to 2010 to three fungicides compared with baseline sensitivity. A, Tetraconazole; $\mathbf{B}$, difenoconazole; $\mathbf{C}$, prothioconazole. For each box, the dotted line represents the mean, the solid line in the box represents the median, the top of each box represents the 75th percentile, the bottom of each box the 25th percentile of $\mathrm{EC}_{50}$ values. Whiskers represent the 90th percentile (top) and the 10th percentile (bottom) of $\mathrm{EC}_{50}$ values. and dots represent outliers.
$0.32 \mu \mathrm{g} \mathrm{ml}^{-1}$ between 2007 and 2009 and the mean $\mathrm{EC}_{50}$ values fell from 0.77 to $0.37 \mu \mathrm{g} \mathrm{ml}^{-1}$ for the same time period (Fig. 1). Although isolates collected in 2007 had higher mean and median prothioconazole $\mathrm{EC}_{50}$ values compared with the baseline (Fig. 1), the percentage of isolates with $\mathrm{EC}_{50}$ values for prothioconazole of $>1.0 \mu \mathrm{g} \mathrm{ml}^{-1}$ has been declining since 2007 (Table 1). The median $\mathrm{EC}_{50}$ values for difenoconazole remained stable during the 5 years that sensitivity was measured, although mean $\mathrm{EC}_{50}$ values have generally been on the rise, as shown by a baseline value of $0.07 \mu \mathrm{g}$ $\mathrm{ml}^{-1}$ increasing to $0.24 \mu \mathrm{g} \mathrm{ml}^{-1}$ in 2010 (Fig. 1).

Effect of tetraconazole $\mathrm{EC}_{50}$ value on disease severity. To explore the relationship between isolate $\mathrm{EC}_{50}$ value and disease severity, 12 isolates with very low, low, medium, or high $\mathrm{EC}_{50}$ values for tetraconazole were used to inoculate sugar beet plants (experiment I). There were significant differences $(P<0.0001)$ among isolates for disease severity (Table 2). Isolates caused a range of disease with no clear correlation between fungicide sensitivity and disease score (Table 3). For example, isolates 09-52, 0960, and 09-347, which represented $\mathrm{EC}_{50}$ classes very low, low, and high, respectively, had similar disease scores (Table 3). Likewise, isolates 08-640, 09-318, and 09-398 that represented $\mathrm{EC}_{50}$ classes very low, medium, and high, respectively, had similar disease ratings (Table 3). When isolates were grouped according to their $\mathrm{EC}_{50}$ value (very low, low, medium, and high), there was no significant difference between the very low and high groups or low and high groups in their ability to cause disease (Table 2) but isolates in the medium $\mathrm{EC}_{50}$ group caused more disease than all other groups (Tables 2 and 3).

Effect of isolate $\mathbf{E C}_{\mathbf{5 0}}$ value on Eminent efficacy. Based on the results from experiment I, isolates 08-640, 09-318, and 09-398, which exhibited similar disease levels in the absence of fungicide (Table 3), were used to assess the effect of isolate $\mathrm{EC}_{50}$ value on the efficacy of the commercial formulation Eminent 125SL at varying rates in greenhouse trials (experiment II). There was a significant effect $(P<0.0001)$ of fungicide rate on disease severity among the isolates (Table 2). Disease severity in plants sprayed with Eminent at concentrations of $<0.01 \mathrm{X}$ resulted in median disease ratings $>8$, regardless of the isolate $\mathrm{EC}_{50}$ value (Table 4). Based on the range of confidence intervals for relative treatment effect, isolate 09-398 (high $\mathrm{EC}_{50}$ ) caused significantly more disease at fungicide concentrations at the field rate $(1 \mathrm{X}), 0.1 \mathrm{X}, 0.01 \mathrm{X}$, and $0.001 \mathrm{X}$ than 08 640 (very low $\mathrm{EC}_{50}$ ) or 09-318 (medium $\mathrm{EC}_{50}$ ) (Table 4). However, in control plants and plants treated with a $0.0001 \mathrm{X}$ dilution of fungicide, there was no significant difference in disease ratings between the isolates (Table 4).

Efficacy of Eminent versus tetraconazole. Because $\mathrm{EC}_{50}$ values are calculated using the active ingredient of each fungicide, we were interested in testing whether tetraconazole, the active ingredient of Eminent, provided the same level of disease control as the commercial product Eminent using isolates 08-640 (very low $\mathrm{EC}_{50}$ ) and 09-398 (high $\mathrm{EC}_{50}$ ) (experiment III). There was a significant effect $(P<0.0001)$ of fungicide type on disease severity among the isolates (Table 2). There was no significant difference in efficacy between tetraconazole and Eminent in plants inoculated with the very low $\mathrm{EC}_{50}$ isolate 08-640 (Tables 2 and 5). However, Eminent provided significantly better $(P<0.05)$ disease control than tetraconazole in plants inoculated with the high $\mathrm{EC}_{50}$ isolate 09-398 (Table 5).

\section{Discussion}

DMI fungicides are widely used to control CLS of sugar beet. Similar to other fungi $(11,16,31,42,44)$, reduced sensitivity to DMIs has been documented in $C$. beticola (1). In this study, we characterized nearly 2,700 C. beticola field isolates collected from all sugar-beet-growing regions of Minnesota and North Dakota for sensitivity to the three most frequently applied DMI fungicides used to control CLS. We found a general increase in the percentage of isolates with medium and high $\mathrm{EC}_{50}$ values for tetraconazole since 2008, which is also reflected in the median $\mathrm{EC}_{50}$ value increasing from 0.06 to $0.32 \mu \mathrm{g} \mathrm{ml}^{-1}$ during this time period. Interest- 
ingly, the number of isolates with medium and high $\mathrm{EC}_{50}$ values for prothioconazole or difenoconazole has remained essentially unchanged or is decreasing, respectively, during the years these fungicides were assessed. It is not clear why the DMIs in this study are exhibiting different trends among the $C$. beticola populations of Minnesota and North Dakota, particularly because cross-resistance is known to occur among triazole fungicides $(9,23,25)$. Although cross-resistance was not observed between all tested DMIs in some isolates of the wheat leaf blotch pathogen Mycosphaerella graminicola (29) or the barley scald pathogen Rhynchosporium secalis (36), Karaoglanidis and Thanassoulopoulos found a high positive cross-resistance correlation between most DMIs used to control CLS (21) but did not test prothioconazole or tetraconazole. The shift to reduced sensitivity to prothioconazole in 2007,1 year prior to release of this fungicide, suggests that cross-resistance occurred between tetraconazole and prothioconazole. Tetraconazole has been in use much longer than prothioconazole or difenoconazole and is the most popular of the three DMIs for CLS control in Minnesota and North Dakota (39), which may have helped to shape the $\mathrm{EC}_{50}$ trends found in this study. Strains with resistance to one DMI fungicide generally are cross-resistant to other DMIs but resistance factors may differ considerably between various DMIs $(21,28)$. A lack of cross-resistance suggests that combining or alternating these DMIs may be useful in controlling CLS and fungicide resistance management. However, additional research needs to be conducted to confirm or refute cross-resistance among the triazoles used in this study for controlling CLS. Although the increase in the number of isolates with tetraconazole $\mathrm{EC}_{50}$ values $>1.0 \mu \mathrm{g} \mathrm{ml}^{-1}$ is a potential concern, fungicides belonging to the QoI class such as Headline (pyraclostrobin) and Gem (trifloxystrobin) are registered for CLS control (39) and may be a valuable supplemental fungicide to control DMI-resistant isolates (22).

The $\mathrm{EC}_{50}$ value at which DMI fungicides lose their efficacy has not been rigorously defined for CLS of sugar beet. Although we had no a priori knowledge of the $\mathrm{EC}_{50}$ value at which fungicide sensitivity is lost in planta, we assumed that isolates with $\mathrm{EC}_{50}$ values $>1.0 \mu \mathrm{g} \mathrm{ml}^{-1}$, which represents more than a 1,000 -fold decrease in sensitivity compared with most baseline isolates collected in 1997 and 1998, were DMI resistant. To test this assumption and help provide more translational meaning to $\mathrm{EC}_{50}$ values, we first inoculated 12 isolates with wide-ranging $\mathrm{EC}_{50}$ values for sugar beet plants and compared the resulting disease ratings (experiment I). Unlike other pathosystems where aggressiveness has been shown to be compromised in DMI-resistant isolates $(11,13)$, we found no obvious correlation between $\mathrm{EC}_{50}$ value and disease severity in the absence of fungicide application. This is in contrast to past studies that associated fitness penalties with DMI resistance in $C$. beticola

Table 2. Analysis of variance-type statistics of disease severity in sugar beet inoculated with Cercospora beticola isolates that represent four different demethylation inhibitor sensitivity classes

\begin{tabular}{|c|c|c|c|c|}
\hline Source $^{a}$ & $\mathbf{d f}_{\mathrm{N}}$ & $\mathbf{d f}_{\mathrm{D}}$ & $\boldsymbol{F}$ & $P>F^{b}$ \\
\hline \multicolumn{5}{|l|}{ Experiment $\mathrm{I}^{\mathrm{c}}$} \\
\hline Isolate & 12 & 60 & 24.01 & $<0.0001 *$ \\
\hline $\mathrm{H}$ vs. VL & 1 & 60 & 3.60 & 0.0626 \\
\hline H vs. L & 1 & 60 & 2.45 & 0.1228 \\
\hline H vs. M & 1 & 60 & 48.6 & $<0.0001 *$ \\
\hline \multicolumn{5}{|l|}{ Experiment $I^{\mathrm{d}}$} \\
\hline Eminent application rates & 17 & 18 & 18.03 & $<0.0001 *$ \\
\hline \multicolumn{5}{|l|}{ Experiment III ${ }^{\mathrm{e}}$} \\
\hline Water control vs. tetraconazole (VL) & 1 & 25 & 50.84 & $<0.0001^{*}$ \\
\hline Tetraconazole vs. Eminent (VL) & 1 & 25 & 0.84 & 0.3694 \\
\hline Water control vs. tetraconazole $(\mathrm{H})$ & 1 & 25 & 5.65 & $0.0254 *$ \\
\hline Tetraconazole vs. Eminent $(\mathrm{H})$ & 1 & 25 & 6.55 & $0.0169^{*}$ \\
\hline
\end{tabular}

Table 3. Effect of tetraconazole 50\% effective concentration $\left(\mathrm{EC}_{50}\right)$ value on disease severity in sugar beet inoculated with Cercospora beticola isolates

\begin{tabular}{|c|c|c|c|c|c|c|}
\hline \multirow[b]{2}{*}{ Isolate $^{\mathrm{a}}$} & \multirow[b]{2}{*}{$\mathrm{EC}_{50}\left(\mu \mathrm{g} \mathrm{ml}^{-1}\right)$} & \multirow[b]{2}{*}{ MDR $^{\mathbf{b}}$} & \multirow[b]{2}{*}{ Mean rank } & \multirow[b]{2}{*}{ Estimated relative effect ${ }^{c}$} & \multicolumn{2}{|c|}{ Confidence interval $(95 \%)$ for relative treatment effect } \\
\hline & & & & & Lower limit & Upper limit \\
\hline \multicolumn{7}{|l|}{$\mathrm{VL} \mathrm{EC}_{50}$} \\
\hline $07-230$ & 0.006 & 4 & 4.17 & $0.27(0.03)$ & 0.223 & 0.332 \\
\hline $09-52$ & 0.006 & 4 & 4.25 & $0.32(0.11)$ & 0.160 & 0.561 \\
\hline 08-640 & 0.008 & 6 & 7.83 & $0.53(0.45)$ & 0.453 & 0.609 \\
\hline \multicolumn{7}{|l|}{$\mathrm{LEC}_{50}$} \\
\hline $09-260$ & 0.073 & 7 & 8.75 & $0.64(0.06)$ & 0.506 & 0.751 \\
\hline 07-558 & 0.074 & 7 & 10.00 & $0.72(0.03)$ & 0.653 & 0.774 \\
\hline 09-60 & 0.081 & 4 & 3.58 & $0.24(0.03)$ & 0.186 & 0.316 \\
\hline \multicolumn{7}{|l|}{$\mathrm{M} \mathrm{EC}_{50}$} \\
\hline $09-344$ & 0.110 & 10 & 12.50 & $0.92(0.03)$ & 0.813 & 0.948 \\
\hline 09-318 & 0.300 & 6 & 7.33 & $0.53(0.04)$ & 0.459 & 0.604 \\
\hline $07-845$ & 0.512 & 9 & 12.00 & $0.88(0.02)$ & 0.823 & 0.915 \\
\hline \multicolumn{7}{|l|}{$\mathrm{HEC}_{50}$} \\
\hline $07-981$ & $>1.0$ & 6 & 8.42 & $0.63(0.06)$ & 0.514 & 0.738 \\
\hline 09-347 & $>1.0$ & 3 & 3.25 & $0.20(0.04)$ & 0.131 & 0.294 \\
\hline $09-398$ & $>1.0$ & 6 & 7.92 & $0.57(0.10)$ & 0.378 & 0.746 \\
\hline
\end{tabular}

${ }^{\mathrm{a}}$ Isolates exhibiting very low $\left(\mathrm{VL} ; \mathrm{EC}_{50} \leq 0.01 \mu \mathrm{g} \mathrm{ml}^{-1}\right)$, low $\left(\mathrm{L} ; \mathrm{EC}_{50}\right.$ between 0.011 and $\left.0.10 \mu \mathrm{g} \mathrm{ml}^{-1}\right)$, medium $\left(\mathrm{M} ; \mathrm{EC}_{50}\right.$ between 0.11 and $\left.1.0 \mu \mathrm{g} \mathrm{ml}^{-1}\right)$, or high $\left(\mathrm{H} ; \mathrm{EC}_{50}>1.0 \mu \mathrm{g} \mathrm{ml}^{-1}\right) \mathrm{EC}_{50}$ values.

${ }^{\mathrm{b}}$ Median disease rating.

c Numbers in parentheses refer to standard error. 
$(18,26)$. For example, Henry and Trivellas (18) documented attenuated virulence in laboratory-induced DMI-resistant $C$. beticola isolates. However, it is not known whether lab-induced mutations in effector genes are attributable to the decreased virulence of DMI-resistant mutants developed in that study. Similar to our results, Nikou et al. (35) characterized five DMI-resistant isolates of C. beticola and found no associated virulence penalties. However, fitness penalties unrelated to aggressiveness may be present in our isolates. Future research assessing fitness parameters such as overwintering ability will be important to confirm whether fitnessrelated penalties exist in DMI-resistant isolates. Importantly, the results of experiment I also identified three isolates from very low, medium, and high $\mathrm{EC}_{50}$ categories that caused similar disease levels on sugar beet. Because $C$. beticola populations are well known to display considerable variability in disease and other characteristics $(2,3,33)$, the identification of isolates from diverse $\mathrm{EC}_{50}$ categories that caused similar disease allowed us to attribute variation in disease levels in subsequent studies to fungicide treatments and not inherent aggressiveness differences unrelated to fungicide sensitivity.

Isolates from three $\mathrm{EC}_{50}$ categories with similar aggressiveness were used to compare Eminent efficacy at field and reduced application rates (experiment II). The high $\mathrm{EC}_{50}$ isolate 09-398 caused significantly more disease than either the medium or very low $\mathrm{EC}_{50}$ isolates in plants protected with field rate concentrations and further dilutions to $0.001 \mathrm{X}$, suggesting that field rate or reduced rates up to $0.001 \mathrm{X}$ will likely favor disease by DMI-resistant isolates. Previous research has shown that reduced rates of the DMI fungicide flutriafol exhibited reduced efficacy to control CLS compared with the full recommended rate (24). In contrast, a recent experiment on the effect of prothioconazole rate on disease caused by $M$. graminicola showed that application rate had no differential effect on disease-causing ability of three high $\mathrm{EC}_{50}$ value isolates (37). The finding that the high $\mathrm{EC}_{50}$ value isolate caused significantly more disease than the medium or low $\mathrm{EC}_{50}$ value isolates at the field rate suggests that the $\mathrm{EC}_{50}$ value of $1.0 \mu \mathrm{g}$ $\mathrm{ml}^{-1}$ is a valid threshold above which isolates may be considered DMI resistant. Future experiments comparing additional isolates from each $\mathrm{EC}_{50}$ class will be useful confirm the $1.0 \mu \mathrm{g} \mathrm{ml}^{-1}$ threshold.

The active ingredient of a fungicide is often used to calculate $\mathrm{EC}_{50}$ values $(4,14,25,26,30,37,38)$. However, we questioned the translational value of calculating $\mathrm{EC}_{50}$ values with fungicide active ingredient because growers apply the commercial fungicide, and

Table 4. Effect of tetraconazole $50 \%$ effective concentration $\left(\mathrm{EC}_{50}\right)$ value on the efficacy of five application rates of the commercial formulation of tetraconazole (Eminent) in sugar beet inoculated with Cercospora beticola isolates

\begin{tabular}{|c|c|c|c|c|c|}
\hline \multirow[b]{2}{*}{ Treatment, isolate $^{\mathbf{a}}$} & \multirow[b]{2}{*}{$\mathbf{M D R}^{\mathbf{b}}$} & \multirow[b]{2}{*}{ Mean rank } & \multirow[b]{2}{*}{ Estimated relative effect ${ }^{c}$} & \multicolumn{2}{|c|}{ Confidence interval $(95 \%)$ for relative treatment effect } \\
\hline & & & & Lower limit & Upper limit \\
\hline \multicolumn{6}{|l|}{ Field rate $(1 \mathrm{X})$} \\
\hline 08-640 (VL) & 0 & 1.25 & $0.04(0.04)$ & 0.03 & 0.12 \\
\hline 09-318 (M) & 1 & 1.75 & $0.07(0.03)$ & 0.05 & 0.11 \\
\hline 09-398 (H) & 5 & 4.5 & $0.23(0.02)$ & 0.19 & 0.28 \\
\hline \multicolumn{6}{|l|}{$0.1 \mathrm{X}$} \\
\hline 08-640 (VL) & 3 & 3.00 & $0.14(0.06)$ & 0.14 & 0.14 \\
\hline 09-318 (M) & 4 & 4.50 & $0.22(0.09)$ & 0.18 & 0.26 \\
\hline 09-398 (H) & 8 & 9.00 & $0.47(0.06)$ & 0.42 & 0.53 \\
\hline \multicolumn{6}{|l|}{$0.01 \mathrm{X}$} \\
\hline 08-640 (VL) & 8 & 11.75 & $0.61(0.03)$ & 0.35 & 0.81 \\
\hline 09-318 (M) & 8 & 9.00 & $0.47(0.02)$ & 0.42 & 0.53 \\
\hline 09-398 (H) & 10 & 17.25 & $0.92(0.01)$ & 0.76 & 0.96 \\
\hline \multicolumn{6}{|l|}{$0.001 \mathrm{X}$} \\
\hline 08-640 (VL) & 8 & 7.50 & $0.38(0.09)$ & 0.25 & 0.54 \\
\hline 09-318 (M) & 8 & 9.00 & $0.47(0.08)$ & 0.42 & 0.53 \\
\hline 09-398 (H) & 9 & 15.00 & $0.81(0.03)$ & 0.66 & 0.90 \\
\hline \multicolumn{6}{|l|}{$0.0001 \mathrm{X}$} \\
\hline 08-640 (VL) & 8 & 9.0 & $0.47(0.13)$ & 0.42 & 0.53 \\
\hline 09-318 (M) & 8 & 10.50 & $0.56(0.01)$ & 0.40 & 0.71 \\
\hline 09-398 (H) & 9 & 16.00 & $0.85(0.01)$ & 0.54 & 0.95 \\
\hline \multicolumn{6}{|l|}{ Water control } \\
\hline 08-640 (VL) & 8 & 11.25 & $0.61(0.13)$ & 0.35 & 0.81 \\
\hline 09-318 (M) & 9 & 15.75 & $0.85(0.03)$ & 0.54 & 0.95 \\
\hline 09-398 (H) & 9 & 15.00 & $0.81(0.08)$ & 0.66 & 0.90 \\
\hline
\end{tabular}

${ }^{\mathrm{a}}$ Isolates exhibiting very low $\left(\mathrm{VL} ; \mathrm{EC}_{50} \leq 0.01 \mu \mathrm{g} \mathrm{ml}^{-1}\right)$, medium $\left(\mathrm{M} ; \mathrm{EC}_{50}\right.$ between 0.11 and $\left.1.0 \mu \mathrm{g} \mathrm{ml}^{-1}\right)$, or high $\left(\mathrm{H} ; \mathrm{EC}_{50}>1.0 \mu \mathrm{g} \mathrm{ml}{ }^{-1}\right) \mathrm{EC}_{50}$ values.

${ }^{\mathrm{b}}$ Median disease rating.

${ }^{\mathrm{c}}$ Numbers in parentheses refer to standard error.

Table 5. Effect of tetraconazole 50\% effective concentration $\left(\mathrm{EC}_{50}\right)$ value on the efficacy of tetraconazole and the commercial formulation of tetraconazole (Eminent) in sugar beet inoculated with Cercospora beticola isolates

\begin{tabular}{|c|c|c|c|c|c|}
\hline \multirow[b]{2}{*}{ Isolate, treatment ${ }^{\mathrm{a}}$} & \multirow[b]{2}{*}{$\mathbf{M D R}^{\mathbf{b}}$} & \multirow[b]{2}{*}{ Mean rank } & \multirow[b]{2}{*}{ Estimated relative effect ${ }^{\mathrm{c}}$} & \multicolumn{2}{|c|}{ Confidence interval $(95 \%)$ for relative treatment effect } \\
\hline & & & & Lower limit & Upper limit \\
\hline \multicolumn{6}{|l|}{$\overline{08-640(\mathrm{VL})}$} \\
\hline Water control & 8 & 5.00 & $0.76(0.05)$ & 0.71 & 0.80 \\
\hline Tetraconazole & 1 & 1.75 & $0.22(0.03)$ & 0.19 & 0.26 \\
\hline Eminent & 1 & 1.33 & $0.16(0.03)$ & 0.13 & 0.19 \\
\hline \multicolumn{6}{|l|}{ 09-398 (H) } \\
\hline Water control & 8 & 5.42 & $0.80(0.04)$ & 0.75 & 0.83 \\
\hline Tetraconazole & 6 & 4.33 & $0.65(0.07)$ & 0.58 & 0.71 \\
\hline Eminent & 4 & 3.17 & $0.41(0.05)$ & 0.34 & 0.46 \\
\hline
\end{tabular}

${ }^{\mathrm{a}}$ Isolates exhibiting very low $\left(\mathrm{VL} ; \mathrm{EC}_{50} \leq 0.01 \mu \mathrm{g} \mathrm{ml}^{-1}\right)$ or high $\left(\mathrm{H} ; \mathrm{EC}_{50}>1.0 \mu \mathrm{g} \mathrm{ml}^{-1}\right) \mathrm{EC}_{50}$ values.

${ }^{\mathrm{b}}$ Median disease rating.

${ }^{\mathrm{c}}$ Numbers in parentheses refer to standard error. 
not just the active ingredient, to help control CLS. To investigate this, we inoculated plants using isolates with either very low or high $\mathrm{EC}_{50}$ values and subsequently treated plants with a commercial formulation (Eminent) or technical-grade tetraconazole. As expected, disease was lower in plants inoculated with a high $\mathrm{EC}_{50}$ isolate treated with Eminent versus tetraconazole alone. However, there was no significant difference between tetraconazole and Eminent on the DMI-sensitive isolate. Although testing more isolates would strengthen our results, this study suggests that the active ingredient alone is adequate to identify isolates with heightened DMI resistance. Moreover, it appears that other ingredients ostensibly present in the commercial formulation, such as wetting agents, spreaders, or stickers, may enhance product performance by facilitating uptake and retention of tetraconazole.

In conclusion, survey results from nearly $2,700 \mathrm{C}$. beticola isolates collected over 5 years shows a general increase in the number of isolates with $\mathrm{EC}_{50}$ values $>1.0 \mu \mathrm{g} \mathrm{ml}^{-1}$ for tetraconazole but not the other DMI fungicides (prothioconazole or difenoconazole). This trend, if continued in future years, will require close monitoring to provide meaningful fungicide recommendations to growers. Moreover, the finding that tetraconazole-resistant isolates can be as aggressive as tetraconazole-sensitive isolates further supports the value of monitoring fungicide resistance in $C$. beticola. The use of $\mathrm{EC}_{50}$ to assess field resistance to DMI fungicides appears to be relevant because our results show that an isolate with $\mathrm{EC}_{50}$ values $>1.0 \mu \mathrm{g} \mathrm{ml}^{-1}$ caused significantly more disease than isolates with low and medium $\mathrm{EC}_{50}$ values after application of Eminent at full field rates. Although our research focused on CLS in North Dakota and Minnesota, resistance to several fungicide chemistries has occurred worldwide in C. beticola $(2,17,21-23,25)$. Sensitivity testing and concomitant fungicide resistance management programs will be necessary to ensure efficacy of all fungicide chemistries for CLS control.

\section{Acknowledgments}

This research was supported by the United States Department of AgricultureAgricultural Research Service CRIS project 5442-22000-042-00D and grants from the Sugarbeet Research and Education Board of Minnesota and North Dakota and the Beet Sugar Development Foundation.

\section{Literature Cited}

1. Bolton, M. D., Birla, K., Rivera-Varas, V., Rudolph, K., and Secor, G. A. 2012. Characterization of CbCyp51 from field isolates of Cercospora beticola. Phytopathology 102:298-305.

2. Bolton, M. D., Rivera, V. V., and Secor, G. Identification of the G143A mutation associated with QoI resistance in Cercospora beticola field isolates from Michigan, United States. Pest Manage. Sci. In press.

3. Bolton, M. D., Secor, G. A., Rivera, V., Weiland, J. J., Rudolph, K., Birla, K., Rengifo, J., and Campbell, L. G. 2012. Evaluation of the potential for sexual reproduction in field populations of Cercospora beticola from USA. Fungal Biol. 116:511-521.

4. Bradley, C., and Pedersen, D. 2011. Baseline sensitivity of Cercospora zeae-maydis to quinone outside inhibitor fungicides. Plant Dis. 95:189-194.

5. Bugbee, W. M. 1981. Sugarbeet Disease Research-1981. Sugarbeet Res. Ext. Rep. 12:155.

6. Bugbee, W. M. 1995. Cercospora beticola tolerant to triphenyltin hydroxide. J. Sugar Beet Res. 32:167-174.

7. Bugbee, W. M. 1996. Cercospora beticola strains from sugar beet tolerant to triphenyltin hydroxide and resistant to thiophanate methyl. Plant Dis. 80:103.

8. Campbell, L. G., Smith, G., A., Lamey, H. A., and Cattanach, A. W. 1998. Cercospora beticola tolerant to triphenyltin hydroxide and resistant to thiophanate methyl in North Dakota and Minnesota. J. Sugar Beet Res. 35:2941.

9. FRAC_-Fungicide Resistance Action Committee. 2011. http://www.frac. info/frac/index.htm

10. Dahman, H., and Staub, T. 1992. Protective, curative, and eradicant activity of difenoconazole against Venturia inaequalis, Cercospora arachidicola, and Alternaria solani. Plant Dis. 76:774-777.

11. De Waard, M. A., and Van Nistelrooy, J. G. M. 1990. Stepwise development of laboratory resistance to DMI-fungicides in Penicillium italicum. Eur. J. Plant Pathol. 96:321-329.

12. Franc, G. D. 2010. Ecology and epidemiology of Cercospora beticola. Pages 7-19 in: Cercospora Leaf Spot of Sugar Beet and Related Species. R. T. Lartey, J. J. Weiland, L. Panella, P. W. Crous, and C. E. Windels, eds. American Phytopathological Society, St. Paul, MN.

13. Fuchs, A., and Drandarevski, C. A. 1976. The likelihood of development of resistance to systemic fungicides which inhibit ergosterol biosynthesis. Eur. J. Plant Pathol. 82:85-87.

14. Garzón, C. D., Molineros, J. E., Yánez, J. M., Flores, F. J., del Mar JiménezGasco, M., and Moorman, G. W. 2011. Sublethal doses of mefenoxam enhance Pythium damping-off of geranium. Plant Dis. 95:1233-1238.

15. Gressel, J. 2011. Low pesticide rates may hasten the evolution of resistance by increasing mutation frequencies. Pest Manage. Sci. 67:253-257.

16. Hamamoto, H., Hasegawa, K., Nakaune, R., Lee, Y. J., Makizumi, Y., Akutsu, K., and Hibi, T. 2000. Tandem repeat of a transcriptional enhancer upstream of the sterol 14alpha-demethylase gene (CYP51) in Penicillium digitatum. Appl. Environ. Microbiol. 66:3421.

17. Hanson, L. E. 2010. Genetics of fungicide resistance in Cercospora and Mycosphaerella. Pages 179-188 in: Cercospora Leaf Spot of Sugar Beet and Related Species. R. T. Lartey, J. J. Weiland, L. Panella, P. W. Crous, and C. Windels, eds. American Phytopathological Society, St. Paul, MN.

18. Henry, M. J., and Trivellas, A. E. 1989. Laboratory-induced fungicide resistance to benzimidazole and azole fungicides in Cercospora beticola. Pestic. Biochem. Physiol. 35:89-96.

19. Jones, R. K., and Windels, C. E. 1991. A management model for Cercospora leaf spot of sugarbeets. No. AF-FO-5643-E.

20. Kaiser, U., Kluth, C., and Märländer, B. 2010. Variety-specific epidemiology of Cercospora beticola Sacc. and consequences for thresholdbased timing of fungicide application in sugar beet. J. Phytopathol. 158:296-306.

21. Karaoglanidis, G. S., and Thanassoulopoulos, C. C. 2003. Cross-resistance patterns among sterol biosynthesis inhibiting fungicides (SBIs) in Cercospora beticola. Eur. J. Plant Pathol. 109:929-934.

22. Karaoglanidis, G. S., and Bardas, G. 2006. Control of benzimidazole- and DMI-resistant strains of Cercospora beticola with strobilurin fungicides. Plant Dis. 90:419-424.

23. Karaoglanidis, G. S., Ioannidis, P. M., and Thanassoulopoulos, C. C. 2000. Reduced sensitivity of Cercospora beticola isolates to sterol-demethylationinhibiting fungicides. Plant Pathol. 49:567-572.

24. Karaoglanidis, G. S., Ioannidis, P. M., and Thanassoulopoulos, C. C. 2001 Influence of fungicide spray schedules on the sensitivity of Cercospora beticola to the sterol demethylation-inhibiting fungicide flutriafol. Crop Prot. 20:941-947.

25. Karaoglanidis, G. S., Loannidis, P. M., and Thanassoulopoulos, C. C. 2002. Changes in sensitivity of Cercospora beticola populations to steroldemethylation-inhibiting fungicides during a 4-year period in northern Greece. Plant Pathol. 51:55-62.

26. Karaoglanidis, G. S., Thanassoulopoulos, C. C., and Ioannidis, P. M. 2001 Fitness of Cercospora beticola field isolates resistant and sensitive to demethylation inhibitor fungicides. Eur. J. Plant Pathol. 107:337-347.

27. Khan, J., Qi, A., and Khan, M. F. R. 2009. Fluctuations in number of Cercospora beticola conidia in relationship to environment and disease severity in sugar beet. Phytopathology 99:796-801.

28. Kuck, K. H., Scheinpflug, H., and Pontzen, R. 1995. DMI fungicides. In: Modern Selective Fungicides. H. Lyr, ed. Gustav Fischer Verlag, Jena, Germany.

29. Leroux, P., Albertini, C., Gautier, A., Gredt, M., and Walker, A.-S. 2007. Mutations in the CYP51 gene correlated with changes in sensitivity to sterol $14 \alpha$-demethylation inhibitors in field isolates of Mycosphaerella gramini cola. Pest Manage. Sci. 63:688-698.

30. Liu, X., Yu, F., Schnabel, G., Wu, J., Wang, Z., and Ma, Z. 2011. Paralogous cyp51 genes in Fusarium graminearum mediate differential sensitivity to sterol demethylation inhibitors. Fungal Genet. Biol. 48:113-123.

31. Luo, C.-X., and Schnabel, G. 2008. Adaptation to fungicides in Monilinia fructicola isolates with different fungicide resistance phenotypes. Phytopathology 98:230-238.

32. Ma, Z., Proffer, T. J., Jacobs, J. L., and Sundin, G. W. 2006. Overexpression

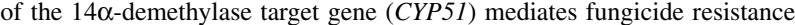
in Blumeriella jaapii. Appl. Environ. Microbiol. 72:2581-2585.

33. Moretti, M., Karaoglanidis, G., Saracchi, M., Fontana, A., and Farina, G. 2006. Analysis of genotypic diversity in Cercospora beticola Sacc. field isolates. Ann. Microbiol. 56:215-221.

34. Munzel, U., and Bandelow, B. 1998. The use of parametric vs. nonparametric tests in the statistical evaluation of rating scales. Pharmacopsychiatry 31:222-224.

35. Nikou, D., Malandrakis, A., Konstantakaki, M., Vontas, J., Markoglou, A., and Ziogas, B. 2009. Molecular characterization and detection of overexpressed C-14 alpha-demethylase-based DMI resistance in Cercospora beticola field isolates. Pestic. Biochem. Physiol. 95:18-27.

36. Robbertse, B., van der Rijst, M., van Aarde, I. M. R., Lennox, C., and Crous, P. W. 2001. DMI sensitivity and cross-resistance patterns of Rhynchosporium secalis isolates from South Africa. Crop Prot. 20:97-102.

37. Sanssené, J., Selim, S., Roisin-Fichter, C., Djerroud, L., Deweer, C., and Halama, P. 2011. Protective and curative efficacy of prothioconazole against isolates of Mycosphaerella graminicola differing in their in vitro sensitivity to DMI fungicides. Pest Manage. Sci. 67:1134-1140.

38. Secor, G. A., and Rivera, V. V. 2012. Fungicide resistance assays for fungal plant pathogens. Pages 385-392 in: Plant Fungal Pathogens: Methods and Protocols. M. D. Bolton, and B. P. H. J. Thomma, eds. Humana Press, New York. 
39. Secor, G. A., Rivera, V. V., Khan, M. F. R., and Gudmestad, N. C. 2010. Monitoring fungicide sensitivity of Cercospora beticola of sugar beet for disease management decisions. Plant Dis. 94:1272-1282.

40. Shah, D. A., and Madden, L. V. 2004. Nonparametric analysis of ordinal data in designed factorial experiments. Phytopathology 94:33-43.

41. Smith, L. J., and Cattanach, A. W. 1982. Response of sugarbeet varieties to various fungicides and fungicide combinations. Sugarbeet Res. Ext. Rep. 13:184-194.

42. Wyand, R. A., and Brown, J. K. M. 2005. Sequence variation in the CYP51 gene of Blumeria graminis associated with resistance to sterol demethylase inhibiting fungicides. Fungal Genet. Biol. 42:726-735.

43. Yan, X., Ma, W.-B., Li, Y., Wang, H., Que, Y.-W., Ma, Z.-H., Talbot, N. J., and Wang, Z.-Y. 2011. A sterol $14 \alpha$-demethylase is required for conidiation, virulence and for mediating sensitivity to sterol demethylation inhibitors by the rice blast fungus Magnaporthe oryzae. Fungal Genet. Biol. 48:144-153.

44. Zwiers, L.-H., Stergiopoulos, I., Van Nistelrooy, J. G. M., and De Waard, M A. 2002. ABC Transporters and azole susceptibility in laboratory strains of the wheat pathogen Mycosphaerella graminicola. Antimicrob. Agents Chemother. 46:3900-3906. 